\title{
LA ESCRITURA COMO RESPUESTA A LA INTOLERANCIA HISTÓRICA. ALINA DIACONÚ ENTRE BUCAREST Y BUENOS AIRES.
}

\author{
POR \\ María del Mar López Cabrales \\ Colorado State University
}

Rumania es el lugar de nacimiento de Alina Bladimir Diaconú, escritora que, considerándose argentina, dice poseer tres patrias: Rumania, Argentina y París. Alina Diaconú, nacida justo después de finalizar la Segunda Guerra Mundial, se marchó de Rumania en 1959 a los catorce años, dejando atrás la experiencia de una infancia y parte de adolescencia vivida bajo el régimen comunista. Rumania estuvo gobernada por líderes como Gheordhiu-Dej (1961-65) y Nicolae Ceausescu (1967-89) que dirigieron el país hacia un socialismo muy sui generis e independiente. Alina Diaconú y su familia sólo vivieron la primera parte del comunismo en Rumania porque en 1959 fueron aceptados como ciudadanos de la Argentina por el presidente Frondizi.

Diaconú ha vivido siempre en países durante épocas históricas de tremendas agitaciones sociopolíticas. Vivió la llegada del régimen comunista en Rumania. Su primera experiencia en Argentina fue bajo el gobierno del radical Arturo Frondizi (1958-62) que prometía mejoras económicas y aseguraba que iba a mantener a los militares en sus cuarteles. Años después llegaría el segundo gobierno populista, ya muy débil, de Juan Domingo Perón (1973-74), que se terminaría metamorfoseando en la dictadura más cruenta de la historia del Cono Sur con el Proceso de Reorganización Nacional (1976-83). Alina Diaconú vivió también en Francia durante las revueltas estudiantiles de mayo del ‘68.

La producción de Alina Diaconú no puede dejar de lado este compromiso con la historia, pero desde la censura de su segunda novela publicada, Buenas noches, profesor (1978), durante el Proceso en Argentina, desarrolló un estilo más metafórico y evasivo de la realidad, sin dejarla de lado totalmente.

Sus libros publicados son: La Señora (1975), Buenas noches, profesor (1978), Enamorada del muro (1981), Cama de ángeles (1983), Los ojos azures (1986), E1 penúltimo viaje (1989) y Los devorados (1992) y la colección de relatos cortos ¿Qué nos pasa Nicolás? (1995). Alina Diaconú también colabora para la prensa argentina en periódicos como La Nación, La Prensa Clarín, La Gaceta, Cultura, Asuntos Culturales, Vigencia y Vuelta. Se ha publicado un libro crítico sobre su obra, que es un conjunto de ensayos prologados por la propia escritora y recopilados por Ester Gimbernat González y Cynthia Tompkins titulado Utopias, ojos azules, bocas suicidas. La narrativa de Alina Diaconú (1993).

En sus textos se construyen sujetos en continuo movimiento, envueltos en situaciones confusas de las cuales intentan desasirse, que intentan conquistar nuevos espacios utópicos 
que se vuelven finalmente distópicos. Los viajes en sus novelas tienen destinos inesperados y tortuosos. La intolerancia, la violencia y la impunidad hacen de los personajes de la narrativa de Diaconú buscadores de salidas y desafiadores de la realidad por medio de la transgresión, lo irreal, lo metafórico y, a veces, hasta lo fantástico. En su narrativa se dan cita multitud de mujeres muy diversas: la Señora de su novela epónima es una mujer mayor, Bruma de Enamorada del muro una adolescente, la diva de Cama de ángeles una artista avejentada y decadente, la personaje innominada de Los ojos azules una mujer de mediana edad en busca de sí misma, y Amapola de El penúltimo viaje un personaje femenino de quien se hace un seguimiento desde su infancia hasta su muerte. Estas mujeres intentan escapar de la corporeidad que las caracteriza. El cuerpo, lugar de autoafirmación del sujeto, se convierte en la narrativa de Diaconú en causa de desgracia; repleto de elementos negativos como excrementos, deshechos, alimentos en descomposición y caracterizado por la diferencia sexual, el cuerpo hace que estos personajes femeninos estén fragmentados y torturados por la indeterminación y la abyección, en el sentido estricto de la palabra, del orden social "patriarcal". No obstante, en la narrativa de Diaconú este orden patriarcal puede ser superado por medio de la locura, el exilio, o la satisfacción que produce la muerte, momento en el que sus personajes se encuentran con la historia y finalmente la entienden.

Gracias a una beca del Centro de Estudios Latinoamericanos de la Universidad de Pittsburgh pude viajar a Buenos Aires y Montevideo en mayo de 1994 y encontrarme con Alina Diaconú en su casa en la Calle Caseros, en el antiguo Barrio de San Telmo, cerca del parque que posee el último ombú bonaerense, según me contaron. Paso a transcribir parte de lo que fue nuestra conversación.

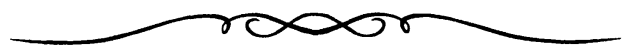

María del Mar López Cabrales: Háblame de tus primeras inmersiones en la escritura $y$ de cómo empezaste a escribir en español.

Alina Diaconú: Yo escribí desde siempre, en los peores momentos de mi vida. Primero escribí en rumano y cuando llegué a la Argentina escribi en francés. Al sentir que me adueñaba del idioma español y que lo podía hablar con cierta fluidez, ya empecé a escribir y a trasladar mis necesidades literarias al idioma español. Cuando viví en París yo ya escribía en castellano y empecé a escribir La Señora, que fue mi primera novela, ya gestada y pensada desde la Argentina. Antes yo había escrito ya dos novelas, una en francés que se llamaba La queja de los repollos y otra en español, Catarsis, que está inédita y creo que va a seguir estándolo por mucho tiempo. Es la historia de amor de un periodista que vive distintas experiencias en distintos países y está escrita con un estilo muy fragmentario, a modo de collage. Finalmente, estos pedazos sueltos se juntan en una especie de mosaico. E1 personaje femenino de quien este periodista se enamora es una fotógrafa intelectual y artística, una mujer muy inteligente que aparece y desaparece en el texto. El peso de la novela lo tiene el periodista pero, más que él, las cosas que le tocan vivir, ya que él aparece más bien como un simple receptor de lo que está viviendo, a veces es como un lector más dentro de la novela. Tal y como está, yo no publicaría Catarsis hoy.

Cuando volví de París, terminé de escribir La Señora, libro que publiqué pagándome la edición porque no me conocía nadie. La recepción de esta novela fue buena, para lo que 
suele ser un primer libro. Recibí cartas de felicitación y hasta me sucedió que subía un colectivo y, de repente, vi que una mujer estaba leyendo mi libro (eso no me volvió a pasar nunca más). Fue tal la emoción, que yo no sabía qué hacer. Primero pensé que le iba a decir que yo era la autora, pero después la mujer cerró el libro, se bajó y se marchó.

M.L.: También te dedicas al periodismo. ¿Cómo empezaste a escribir para la prensa?

A.D.: El periodismo fue algo raro que me sucedió, porque yo nunca quise escribir para la prensa. El diario de La Opinión, que en aquel momento era opositor del peronismo, me llamó para hacerme una entrevista a raíz de la publicación de Buenas noches profesor [1978]. El reportaje fue muy polémico porque el periodista fue bastante agresivo - no fue un reportaje complaciente, en absoluto-y llamó la atención. A raíz de eso me llamaron de la revista Gente, un semanario frívolo que ahora lo es más todavía, y me dijeron que les escribiera cada quince días una columna de opinión sobre las cosas cotidianas. Esto me dio popularidad, porque Gente se publica en diferentes países. Así fue mi comienzo en el periodismo, porque yo no soy periodista y siempre lo aclaro. Escribo para la prensa sólo notas de opinión y he hecho reportajes a escritores que me interesaban. Probé notas periodísticas, porque me las pidieron dos veces y las pagaban bien, pero me di cuenta de que yo no tenía nada que ver con eso.

Después, fui escribiendo cada vez más y como yo viajaba mucho, publiqué reportajes de personajes como Cioran, Ionesco, Borges y Sarduy, entre otros. Colaboré en periódicos como Clarín, La Nación y La Prensa. He publicado muchos trabajos, no han sido sólo colaboraciones esporádicas.

M.L.: ¿Cuál es la división que haces entre lo periodístico y lo literario?

A.D.: Yo creo que lo primero se dio porque me proporciona una comunicación más fluida y más inmediata con las personas que leen, y eso me ha hecho mucho bien. E1 libro, sin embargo, tiene un camino más lento y una respuesta más lenta también. El periodismo me ayudó a descubrir una cosa que yo no tenía nada clara y que ahora me llama la atención, y es que en algunos de mis artículos hay puntos de contacto con el ensayo y a mí me interesa muchísimo este género. Aunque yo no me considere ensayista, siempre me fascinó el ensayo escrito por otra gente.

M.L.: Tú naciste en Bucarest. ¿Qué recuerdas de tu infancia? ¿hay algo que te marcara en aquella época?

A.D.: Mi vida está marcada por un hecho fundamental que es la partida de mi país natal, Rumania, y que hace que las cosas sucedan antes o después de este hecho. Yo tenía catorce años y estaba en una edad en la que era chica pero no del todo porque ya tenía la vivencia de una infancia en Bucarest, en una casa antigua con un jardín enorme. Fui hija única, lo cual me ayudó a desarrollar exacerbadamente mi imaginación y crear un mundo propio en el que jugar conmigo misma. Esto fue un desafío para mí y me hizo mucho bien, porque después en mi vida hubo muchos desafios, entre ellos la adaptación a un país nuevo, a una lengua y una cultura nuevas. En Bucarest yo vivía en un ambiente muy particular porque mi padre era crítico y coleccionista de arte y mi casa era como un museo con una pinacoteca de más de cien cuadros. Por tanto, me habitué a vivir entre cuadros y a estar entre pintores y escritores. Mis padres tenían una vida social muy activa y por eso crecí entre gente grande, oyendo conversaciones intelectuales que, sin darme cuenta, me fueron educando.

Mi familia era de clase media intelectual, sin ninguna tendencia política concreta. Sólo recuerdo que mi abuelo materno había sido un gran médico que hizo muchas obras sociales 
y lo llamaban el médico de los pobres (una de las calles de Bucarest tiene su nombre). Mi padre era un escéptico político total. Este escepticismo quizás se debió a que mi familia vivió de muy cerca las dos guerras mundiales. Yo nací después de la Segunda Guerra y también cargué inconscientemente con el peso de esas dos guerras que dejaron huella en toda Europa.

De mi infancia recuerdo que vivía en contacto con la naturaleza y que me podía pasar horas mirando a los caracoles como dejaban la baba en el piso. Tenía un amor inmenso por la naturaleza que para mí era el show más divertido que se podía observar. En Bucarest, yo viví entre muchos gatos. Sin entender nada porque yo era muy chica, veía las escenas de amor impresionantes de los gatos y cómo volvían magullados, con pedazos de piel arrancados.

Después, para mí fue muy importante el mundo de las mucamas que aparece en mi novela El penúltimo viaje [1989], porque cuando era chica el mundo de los afectos venía a través de ellas. Casi simpre había dos, una mucama y una cocinera. Durante el régimen comunista también teníamos mucamas, porque la casa era muy grande, mis padres trabajaban y el gobierno les permitía tener esa ayuda. Yo tenía una relación entrañable con la cocinera porque me gustaba el mundo creativo de la cocina, les ayudaba picando las cosas, añadiendo especias y de paso me aprendía las recetas. El mundo de las mucamas era fascinante para mí por las historias increíbles que me contaban. Todas ellas eran muchachas que venían de Transilvania, de cultura húngara, y llevaban sus trajes típicos. En su mayoría eran campesinas que buscaban ganar más dinero en la capital trabajando en las casas. Ellas seguían siendo campesinas en todos los sentidos y me proporcionaban un mundo repleto de historias impresionantes que me encantaba escuchar e imaginar.

M.L.: ¿Escribias en rumano cuando eras pequeña?

A.D.: Siempre fui muy rebelde y daba contestaciones muy fuertes a mis padres. Esa rebeldía me llevó a escribir desde muy chica. Por otro lado, me enseñaron a leer y a escribir a los cuatro años y además tenía una profesora particular de francés como segundo idioma. Recuerdo que a los diez años mis padres ya me daban Shakespeare y Tolstoi. "Ya tenés que leer cosas más serias" me decían, y me daban esas lecturas. Yo leí Romeo y Julieta a los diez años. Leí mucho a los rusos. Me encanta Dostoevski, Andreiev, Tolstoi y el teatro de Gogol, y Todorov, pero especialmente me enganché con la angustia existencial del primero. Por otro lado, me marcaron mucho los cuentos de hadas porque tenía una niñera alemana que me los leía. Creo que mi producción tiene que ver mucho con eso. Mi introducción al mundo del libro fue a través de los cuentos de hadas, recuerdo el grosor de los libros, los colores, los monstruos y las hadas. Había muchos cuentos del folklore rumano, de leyendas anónimas transmitidas por tradición oral y recopiladas por Ispirescu. Recuerdo que uno de los cuentos se llamaba "Juventud sin vejez y vida sin muerte", un cuento de hadas fabuloso y complicadísimo que me llamaba mucho la atención porque veía que era un poco lo que toda la gente ambicionaba. También me leían unos cuentos franceses (que a mí no me gustaban nada porque eran sobre la chica buena y la chica mala), los de La biblioteca rosa de la condesa de Ségur. Lo mío era el mundo de lo fantástico y del misterio.

M.L.: Veo que también tienes una historia con Drácula ¿por eso tocas el tema de las plantas carnivoras en tu última novela Los devorados [1992]? 
A.D.: El mito del vampirismo me parecía interesante. Me fascinaron siempre las historias que escuchaba en Rumania de gente endemoniada sobre la que clavaban una estaca en el corazón para sacarle el mal cuando moría, porque si no, el demonio podía pasar a otras personas. Me dejaban perpleja todas las historias que escuchaba de las criadas de Transilvania: los mitos del hombre lobo y del séptimo hijo varón que podía ser lobizón. Después, los mitos griegos que leí a través de Robert Graves también me influyeron. Todo lo que sea mito me interesa, más que la historia. Me fascinó la idea de los dioses griegos, tan sanguinarios, $\tan$ iracundos y tan humanos a la vez.

M.L.: ¿Por qué se fue tu familia de Rumania? ¿Se tuvieron o se quisieron ir?

A.D.: No, se quisieron ir. Digo se quisieron, porque yo no me quería ir. A esa edad yo ya tenía mi mundo de amigas del colegio y estaba en plena pubertad, una época difícil en la que salís de la infancia y empezás a ser mujer, pero no lo sos todavía ... es una época de mucho conflicto. Entonces, si a eso le agregás una ruptura tan fuerte como irse a la Argentina, que para mí era como irse a la China, te podés imaginar. Mis padres vinieron con más ilusión porque en Buenos Aires vivía una tía, hermana de mi madre, que se había ido después de la Segunda Guerra Mundial, a quien le fue bien. Mis padres siempre se mantuvieron en contacto con ella y después de la muerte de mis abuelos, nos quedamos solos en esa casa grande a la que después empezaron a mandar gente desconocida.

M.L.: ¿Como en tu novela $\mathrm{El}$ penúltimo viaje ...?

A.D.: Exactamente. En esta novela hay cosas que son inventadas, pero estas personas no lo son. Viendo que la casa era grande para nosotros y que había otras dos o tres habitaciones libres, el gobierno mandaba gente a vivir con nosotros. La identidad de estas personas nos era absolutamente desconocida. Después de la nacionalización de la propiedad en Bucarest [1947], mi familia se quedó en la casa, pero teníamos que pagar como si fuéramos inquilinos. Aunque se vivía en un ambiente de mucha desconfianza, sinceramente a mí no me influyó de manera negativa. Para mí era algo medio divertido: gente nueva que pasaba por la casa con historias diferentes y fascinantes. Sin ir más lejos, una vez había una inquilina que había sido bailarina y a mi me fascinaba hablar con ella. De todas formas, si sentía que mis padres me transmitían esa desconfianza ¿qué puede pasar? ¿qué pueden decir estas personas? ¿quiénes serán? ¿serán espías? Recuerdo que había que estar hablando siempre en voz baja. Yo transmití todo eso en El penúltimo viaje.

M.L.: Dijiste que tus padres no tenían ningún tipo de compromiso político, ¿cuál era la razón para tener miedo?

A.D.: No. El problema era que el miedo estaba enquistado porque no se sabía qué podía pasar. De repente podía haber una denuncia y nadie iba a comprobar si eso era verdad o no y, bueno, se podía pasar muy mal. Había mucha impunidad y la autodefensa era imposible cuando se estaba fichado por alguna razón. El miedo era una cosa terrible.

M.L.: ¿Por qué se marchó tu familia de Bucarest? ¿Por la situación política? No me contestaste a esa parte de mi pregunta.

A.D.: Bueno, la situación política, sí. Había varios problemas pero yo nunca voy a saber exactamente qué pasó.

M.L.: ¿No te dijeron la verdadera razón?

A.D.: Sí, sí. Siempre me dicen, pero es como si los argumentos que me dan ... Yo no puedo creer que todo fuera tan sencillo, digamos, para decidir una cosa tan fuerte. Los 
argumentos que toda mi vida oí fueron dos: uno era que mi padre escribía y era redactor en jefe en Rumania de una revista de arte que se hacía para el exterior. Por aquella época en Rumania, los pintores pintaban siguiendo el estilo denominado Realismo Socialista y tenían que pintar sobre los obreros o escenas de trabajo, no se podía pintar una naturaleza muerta o un paisaje. Los artistas que no se plegaban a eso no podían hacer nada, y muchos pintores conocidos que seguían ese tipo de temática por imposición, no por vocación, producían verdaderos desastres. Mi padre no escribía sobre estos pintores, sino sobre los clásicos. Un día lo llamaron y le dijeron: "Escriba sobre la gente de hoy". Entonces, mi padre llegó a casa ese día y le dijo a mi madre: "Llegó el momento de irse", porque cuando te llamaban había ya una amenaza latente.

Otra razón que mis padres me dieron (y yo creo que las dos razones son reales y que se juntaron a otras de tipo psicológico, de hartazgo, de cansancio, etc.) fue que en Rumania a los quince años había que pasar un examen muy difícil para ingresar en la secundaria. En este examen la gente estaba dividida entre los que tenían origen sano (hijos de campesinos y obreros) que entraban al examen ya con una puntuación más alta y los que no tenían origen sano. Yo no lo tenía porque era hija de intelectuales y para pasar ese examen tenía que superar esos puntos extras, lo cual era bastante difícil. Tenés que tener en cuenta que era el comienzo del régimen y estaban muy estrictos en esta serie de cosas. Mis posibilidades de futuro, carrera, estudios, estaban cortadas y mis padres pensaron que ésa era otra causa por la que debían marcharse.

M.L.: ¿Tuvo tu mamá problemas con el régimen comunista?

A.D.: No, ninguno. Mi madre era muy buena en su trabajo. En ese momento había en Rumania la Asociación de los Artistas Plásticos a la que los artistas tenían que estar afiliados. Aunque esa asociación no tenía participación política, había que tomar un curso obligatorio de marxismo-leninismo. Mi madre siguió este curso, acoplándose a las circunstancias, porque esto significaba tener trabajo. Ella toleró mejor que mi padre el cambio, porque papá tenía que trabajar con ideas y mi madre no tenía un compromiso intelectual tan fuerte. A ella el estado le encargaba diseñar regalos para las personalidades que visitaban Rumania, como por ejemplo Stalin, o para las personalidades del propio país, como el presidente Gheorghe Gheorghiu-Dej [1961-1965]. Le pedían que hiciera encuadernaciones para regalos y le pagaban muy bien.

M.L.: Te pregunto esto, porque en tu novela El último viaje el compromiso político del padre de la familia es muy fuerte y es, a la vez, el motivo de su destrucción. ¿Qué significan todas estas estatuillas que se encontraban en el escritorio del padre y que cambiaban de rostro constantemente?

A.D.: Claro. Eso en mi casa no pasaba porque nadie estaba politizado y yo escribí sobre una familia en donde el padre estaba totalmente absorbido por "la Cúpula", el partido. Lo que pasaba era que la gente subía y bajaba de golpe. Un día alguien era el líder y al siguiente ya no existía más. Yo recuerdo que cuando Stalin murió yo lloré, porque era como un abuelo bueno que simpre estaba abrazado a los niños; además, teníamos su retrato colgado en la pared de la escuela. Después de unos años empezó el tema de que Stalin había sido un horror, el asunto del culto a la personalidad y de que había que tirar todo eso. En Bucarest había un monumento a Stalin de catorce metros de altura y lo derrumbaron por completo. El tema de las estatuas en mi libro lo utilicé de una manera metafórica, porque 
cambiaban los retratos de los líderes políticos y la gente que estaba en el partido tenía que seguir ese tren. Yo escribí sobre una familia en la que el padre era un hombre del partido y lo defenestraron. Había denuncias que no se sabía de dónde venían, pero cuando alguien se convertía en enemigo del pueblo, allí se terminaba no sólo su carrera, su vida. A nosotros no nos pasó eso directamente.

Mi libro El penúltimo viaje fue como algo medio profético, porque en el tiempo que yo escribí esta novela no había saltado el conflicto en los Balcanes, ni se había originado la caída de los regímenes comunistas en la llamada Europa del Este. Tres meses después de la publicación de El penúltimo viaje cayó el muro de Berlín. Yo saqué el tema de los países del Este porque nunca había escrito sobre ello y siempre me decía que tenía que hacerlo en algún momento, tenía que contar esa experiencia vivida hasta los catorce años. Anteriormente, con Cama de ángeles [1983] también anticipé el tema de la androginia y del transexualismo. Fue un libro muy raro para ese momento, porque ese tema no estaba todavía tan difundido acá en la Argentina.

M.L.: ¿Cómo recuerdas tu partida, el momento en el que tuviste que tomar tus cosas y marcharte?

A.D.: Mis padres estaban en continua correspondencia con esa tía mía que estaba en Buenos Aires y un día me avisaron de que iban a hacer una solicitud para salir del país, aunque no era tan fácil salir. Mis padres rellenaron la solicitud que normalmente llevaba meses o años recibir contestación, casi siempre negativa. Esta tía mía que vivía en Buenos Aires tenía muchos contactos diplomáticos y la partida nuestra se produjo porque ella consiguió que el gobierno argentino (por aquel entonces estaba Frondizi) le pidiera al rumano que nos permitiera salir.

A mí me pasó una cosa muy curiosa. Hacía mucho tiempo que se había mandado ese papel y mis padres tenían en la cabeza irse. Un día de primavera yo volvía del colegio al mediodía y tenía que atravesar el jardín de mi casa. Entré por la puerta de servicio y vi que no había nadie en la cocina, la casa estaba desierta. Entonces yo pensé: ahora voy a llegar a mi cuarto y voy a encontrar a mi madre agarrada a la cabeza con la carta delante. Así fue, tal y como yo lo imaginaba. Entré en mi cuarto y mi madre me dijo que la petición había salido favorable. Yo le dije:

"Yo no me voy" y, mi madre me respondió: "No, tenés que ir". Unos días después había que firmar un papel en el que tenía que estar mi firma también y yo dije que no iba a firmar porque no me quería ir. Entonces me dieron muchísimas explicaciones. Yo lo recuerdo todo como una cosa muy violenta porque me hicieron firmar en contra de mi voluntad. Así salí de Rumania.

Pero yo tengo borrado todo eso mucho, porque mis padres me mandaron a casa de una amiga mía que era como una hermana. Sólo recuerdo el último día en Bucarest, cuando tomamos el tren para ir a París. Yo pasé un día horroroso de despedidas, llorando todo el tiempo. Aunque estaba resignada, sabía que todo lo que iba a encontrar no me iba a gustar en absoluto. A pesar de lo que me decían, no les creí nada. Toda la casa enorme había quedado reducida a un baúl. Todos los cuadros de mi casa se dieron al museo porque eran considerados patrimonio nacional. Después llegamos a París. Por aquel entonces todo el mundo en Rumania hablaba de las maravillas de esa ciudad. París no me gustó nada, me pareció una ciudad gris, sucia, sin sol, siempre lluviosa. Acá llegué y me llevaron a la 
Avenida Santa Fe para que viera la elegancia de las vidrieras y a mí me pareció todo un horror. La Argentina me pareció un espanto y esto me duró dos años.

Yo escribía, tenía un cuaderno y lo escribía todo durante ese período de mi vida. En los primeros momentos escribía mis sueños en rumano. Cuando escribía cosas literarias acá, como no hablaba español, lo hacía en francés. Después escribí mucho teatro y finalmente lo abandoné y me metí de lleno en la novela. Ese trance de adaptación fue muy duro y lo escribía todo porque era muy introvertida. A mi padre le mostraba algunas cosas, pero eran muy íntimas y me escondía para escribirlas y nadie más que yo sabía que existían. Destruí todos los escritos desesperados cuando empecé a estar bien acá porque no quise recordar ese sufrimiento.

\section{M.L.: ¿Cómo fue tu adaptación a la Argentina?}

A.D.: En realidad, yo me adapté pronto al colegio. A los diez días de llegar a la Argentina me metieron en un colegio de monjas alemanas, con una disciplina muy fuerte, pero al lado de lo que era la disciplina y el rigor rumanos, este colegio fue para mí un juego de niñas. Para mí el problema fue el idioma, aunque lo aprendí bastante rápido. A los tres meses ya hablaba castellano - con errores, claro.

Recuerdo perfectamente mi primera impresión al llegar al colegio. Me correspondía entrar en el segundo año de Liceo, pero no me reconocieron los años en Rumania y me hicieron entrar en sexto, que era el último año de la primaria, con compañeras dos años más pequeñas. Todo era distinto, porque yo era un bicho rarísimo para ellas y viceversa. Además estaba sola y sin hablar el idioma. No entendía nada. Ahí mi salvación fue una chica que hablaba francés, la hija de la directora de cine María Luisa Bemberg. Esta chica me traducía todo lo que las niñas me preguntaban, porque me volvían loca en los recreos y lo único que yo sabía decir era "No entiendo". Mis compañeras me cargaban cuando hablaba español porque cometía errores, pero empecé a socializar y se dio una buena relación con las chicas porque yo era un ser extraterrestre, pero a la vez era el centro de atracción. Yo les pedía siempre que me corrigieran cualquier palabra que les dijera mal y eso me ayudó muchísimo porque yo soy muy exigente. También fue importante mi sentido del humor, porque yo no me ofendía si se reían de mi mala pronunciación. Nunca me sentí inferior, ni tenía esa cosa de orgullo ... no. A mí me causaba gracia, me reía de mí misma.

En sexto grado había un libro para todas las materias y yo me estudiaba de memoria el texto por la fonética, sin entender nada, lo daba y me sacaba un diez. Mi tía me corregía la pronunciación y eso me ayudó por que me fue metiendo el idioma fonéticamente. Yo sacaba muy buenas notas al principio porque estudiaba como un papagayo, y la parte de números para mí era muy fácil, ahí no tenía problemas.

Después empecé a dar exámenes libres para recuperar esos dos años y lo conseguí. Cuando terminé quinto en el colegio pedí que me dejaran hablar. Salí al escenario y conté cómo había sido mi llegada. Todo el mundo lloraba y fue muy emocionante. Para mí fue importantísima toda esa época en la que hice tantas amigas y empecé a adaptarme a un país y una sociedad absolutamente distintos para mí.

A los dieciocho años, cuando terminé el colegio, empecé a trabajar con una productora de publicidad. Iba a la Facultad de El Salvador de noche, hacía la carrera de Comunicación y Publicidad, y trabajaba de día, porque necesitábamos plata. Mi padre ganaba poco dinero, porque era empleado de oficina. Y, sin embargo, yo empecé a ganar mucha plata en 
publicidad. Cuando terminé la universidad, París volvió a mí como esa cosa fascinante, a pesar de todo. Entonces me lo pensé y me dije: "Me voy a pasar un tiempo allá y a lo mejor me quedo a vivir". Yo tenía que vivir esa experiencia y me fui, pero al año ya no daba más. Extrañaba muchísimo la Argentina.

M.L.: ¿Cuándo fue eso?

A.D.: Fue en 1968.

M.L.: ¿Viviste la revolución de estudiantes allí? ¿qué recuerdas?

A.D.: Recuerdo las calles tapadas, el movimento, la inquietud de la gente joven ... pero yo en la cosa política no me enganché.

M.L.: Pero tu vida ha estado signada por las convulsiones sociopoliticas: Rumania, Paris y luego Buenos Aires. ¿Por qué te fuiste de París?

A.D.: Sí, sí. Recuerdo que un día estaba tomando el subte y a mí siempre me fascinó cuando sale a la superficie y se ve todo el Sena y París; cada vez que se repetía esta imagen yo me quedaba pensando " ¿Qué locura!" Un día yo iba a trabajar y el subte salió y era como si no existiera, ya no me decía nada. Ahí me di cuenta de que ya no me importaba estar en París, de que me daba lo mismo. ¿Qué diferencia había entre vivir en París y vivir en Buenos Aires? Todo era ya una rutina. Fue una experiencia extraordinaria en medio de ese ambiente revuelto políticamente y me sirvió pare estrechar mis lazos de amistad con Ionesco, a quien conocía ya de antes. El problema fue que me empezó a faltar la cosa afectiva que en Francia no percibía porque los franceses son muy fríos. Además, en Francia había permanentemente una exigencia intelectual, cada conversación era como dar un examen, siempre había que estar brillante, actuando, y esto era muy cansador. La Argentina para mí era una cosa más natural, más tranquila, más entrañable. De exigencias y violencia ya estaba harta y me volví chocha. Me volví y me casé con Ricardo [Cordero].

M.L.: Volviendo a la Argentina, una de tus novelas, Buenas noches, profesor fue censurada durante el Proceso de Reorganización Nacional.

A.D.: Sí, me enteré porque lo leí en el diario. Era una medida municipal que declaraba que mi novela era "un libro de exhibición limitada". Esto significaba que el librero lo podía tener, pero no lo podía exhibir y, normalmente, al saber que el libro venía con problemas, el librero lo mandaba de vuelta. Era una manera muy sutil de censurar.

M.L.: ¿Nunca sentiste la necesidad de saber por qué consideraban tu novela censurable?

A.D.: Sí. Además, Buenas noches profesor era un libro recién salido y hasta había recibido un premio. Yo me puse muy mal y me dije que tenía que averiguar y preguntar. Todo el mundo me aconsejó que no lo hiciera, que era muchísimo peor tratar de indagar qué había pasado. Era un tiempo de mucho terror. Yo había tenido una larga educación en el terror, y sabía que llegado a determinado punto no se podía hacer nada más. Así terminó todo.

Me parece que el libro no hace ninguna crítica tan explícita que la censuraran. Creo que el libro fue malentendido. Quizá leyeron la palabra "incesto" de la contraportada y no les gustó la idea de la relación entre un profesor y una alumna. Quizá les pareció demasiado inaceptable moralmente. ¡Cómo si nunca hubiera pasado!

M.L.: También cuentas la muerte de Perón y calificas a la Argentina como un país "de brujos y cabareteras". Estas son dos menciones muy explícitas, ¿no te parece? 
A.D.: No sé honestamente, porque se supone que los militares sacaron al peronismo, aunque todo ya estaba muy cantado y tras la muerte de Perón hubo un vacío de poder muy fuerte. No sé, a lo mejor no les gustó la desmitificación del país al que califico lleno de fetichistas, mitificadores y mitómanos. Buenas noches, más allá de una crítica a un gobierno concreto, es una crítica a la sociedad entera.

Después de esto, empecé una autocensura más fuerte porque suicida nunca fui y podía controlar más o menos lo que escribía.

M.L.: Pero tus personajes sí que lo son.

A.D.: Sí tengo bastantes personajes suicidas por ahí que deben ser los suicidas que tengo dentro. Pero en la vida real me cuidé bastante, porque además venía ya desde Rumania con una fuerte preparación pare el autoritarismo. La censura de ese libro fue decisiva en mi vida literaria, porque yo cambié mi estilo. Si bien mis dos primeros libros [La señora, 1975 y Buenas noches, profesor, 1978] eran más cercanos a la vida real, más sociales, y en ellos presentaba mundos marginales como el de la prostitución, después de esa censura me refugié directamente en la metáfora y hubo un cambio bastante grande hacia la literatura fantástica, aunque mis libros tampoco son totalmente fantásticos. Libros publicados durante la dictadura, después de la censura de Buenas noches, profesor fueron Enamorada del muro [1981] y Cama de ángeles [1983]. El primero es sobre el mundo de la adolescencia, sobre una chica que deambula por la ciudad, y en esta novela ya aparece la cuestión de una secta extraña y el personaje deforme de la enana. En el segundo toco lo histriónico y lo fantástico.

M.L.: Sin embargo, la escena final de tu siguiente novela, Los ojos azules [1986], es totalemente alusiva a lo sucedido en la Argentina, es una tortura y un interrogatorio policial.

A.D.: Por supuesto, mi despegue no es total, porque siempre hay una base de realidad. Pero de todos modos, mi forma de contar se hizo más secreta y ambigua desde que censuraron Buenas noches, profesor. Estas novelas, por otra parte, también permiten participar más a las personas que lo leen, porque son libros con finales abiertos. Desde la censura de este libro, e incluso después de la llegada de la democracia seguí escribiendo con este estilo.

M.L.: La critica ha considerado tus tres novelas Enamorada del muro, Cama de ángeles $y$ Los ojos azules como una trilogía.

A.D.: Sí. Yo me di cuenta de que con las tres novelas había cerrado un ciclo. El siguiente libro, El Penúltimo viaje rompió por completo con mi anterior producción. Los tres libros tocan el tema de la identidad. En Enamorada me despego más de la realidad con la alucinación de los helados como sustitutos de la droga para Bruma, la personaje principal, que recibe este nombre por la bruma de la confusión en la que está envuelta. En Cama de ángeles, Ángel/a plantea el problema de la identidad sexual y en Los ojos azules trato de una mujer sin nombre que se va a una isla perdida para encontrarse a sí misma. El otro tema fuerte de los tres libros es el fatalismo del destino. Los personajes siguen un camino del cual no se pueden apartar aunque el destino sea siempre la tragedia. Están envueltos en una especie de ola que los lleva de un lado para otro: Bruma deambulando por la ciudad, Ángel/a con la diva queriendo ir a París pero cayendo en un mundo fantasmagórico y entrando casi en los infiernos, y en los Los ojos azules, un personaje que va a un hotel de cinco estrellas y que termina en una sesión de tortura. 
También los tres libros tienen que ver con el ambiente político de la época. La idea de la secta de los que se comen las uñas y persiguen a los que no se las comen en Enamorada. En Cama de Angeles, la diva destronada que camina en una ciudad devastada y entra en un manicomio donde hay un personaje que es la semblanza de un milico, tiene un hijo desaparecido. En Los ojos azules todo termina en tortura y violación de la personaje central. Estos tres libros son narrados a un nivel simbólico, y presentan historias fantásticas narradas en escenarios no reconocibles ni concretos. Quizá por eso los dos primeros no fueron censurados. Yo sentía la necesidad de dar un testimonio de lo que estaba sucediendo. Era una manera de protestar sin ser suicida. Yo viví toda mi vida desde chica en un clima de mucha intolerancia. De grande quise dar el testimonio de esa cosa terrible que es la violencia, la impunidad. Lo mío fue salir de guatemala y meterme en guatepeor.

M.L.: Como llevabas tú personalmente el tema de la represión, del hecho de que la gente no se pudiera reunir, de las redadas policiales, de la violencia.

A.D.: Bueno, yo nunca he tenido muchos amigos escritores, para empezar, y los que o tenía no estaban tampoco en la militancia política. Recuerdo que una sola vez se hizo una reunión de escritores donde había gente militante y yo sentí un poco de miedo porque nos juntamos y alguien vino diciendo que había visto un auto sospechoso esperando fuera del edificio. Sentí miedo. Todo era muy paranoico.

M.L.: Háblame del tema del exilio y la producción literaria durante el Proceso en Argentina.

A.D.: En ese momento se planteó la cuestión del exilio interno y del externo. Se discutió sobre los escritores que se fueron del país y que por irse se consideraron más valientes, y de los que se quedaron y que supuestamente fueron colaboracionistas con el régimen. Esta visión me pareció siempre bastante simplista y maniqueísta. Yo creo que todos sufrimos, los que se fueron y los que nos quedamos. Cada persona hizo lo que pudo. Los que no pudieron aguantar y fueron amenazados directamente se fueron, y el resto se quedó pero no lo pasó nada bien. Hubo también mucha gente que explotó su condición de exiliado y eso le ayudó a que se le abrieran puertas y publicaran en otros idiomas. En algunos casos esa desventaja del exilio se convirtió en ventaja, pero sólo en algunos casos. Finalmente, para mí lo que importa es quién escribió, dentro o fuera del país, porque la vida de todos y de todas es interesante, pero lamentablemente lo que importa es la producción y la calidad de ésta.

M.L.: ¿Cuáles son tus influencias literarias más fuertes?

A.D.: Te he comentado ya de Ionesco, y también me influyeron Bertolt Brechty Kafka. Yo considero que en el fondo me influye todo porque siempre se limita la influencia a lo literario y eso también limita lo que es tu vida. A mí me influyen el cine, la pintura, las noticias. Me han influido directores de cine como Bergman y Fellini. El Pop Art, que yo viví a finales de los sesenta y que era muy revolucionario porque mezclaba el consumo con el arte: Andy Warhol, por ejemplo, fue un fenómeno muy interesante para mí. Cuando se escribe, se hace con todos los sentidos, teniendo en cuenta las preferencias artísticas, los escritores, los pensadores que has leído, el cine, la vida cotidiana, todo. Cuando se vive en un lugar se está en una especie de baño de inmersión y algunas cosas te llegan más y otras menos. Yo vine de Rumania con la influencia de los escritores clásicos franceses y los rusos y luego fui teniendo otras experiencias y fui adquiriendo nuevas influencias. En Buenos 
Aires me influyó el tango. Me parece uno de los bailes más fascinantes: la sexualidad, la voluptuosidad ... es extraordinario. De la Argentina me influyó también el folklore. Cuando llegué acá hubo un escritor argentino que me gustó mucho que fue Roberto Arlt. También me influyó mucho Cortázar y a Borges lo descubrí bastante después.

De lo latinoamericano, en general, me interesó mucho la poesía de Neruda y de Vallejo. A los escritores del boom los leí. Me gusta mucho Carpentier. De los cubanos me interesó mucho esa cosa tan barroca y recargada, como Lezama Lima. Severo Sarduy también me gustó y me fascinó la idea de que siguiera siendo cubano a pesar del exilio. También me interesaron mucho las escritoras brasileñas como Clarice Lispector y Nélida Piñon. De las escritoras argentinas, Silvina Ocampo me entusiasmó por afinidades literarias. Con los poetas he tenido muchos lazos de unión también, Alberto Girri, Olga Orozco y Enrique Molina, entre otros.

M.L.: Sé que fuiste muy amiga de Marta Lynch. Su literatura fue muy testimonial y autobiográfica, cosa que tú no haces. Marta Lynch estaba muy preocupada por reflejar en su obra lo social de una manera muy abierta y directa. ¿Cómo os conocisteis?

A.D.: Sí. Marta era una mujer con mucho vigor. La conocí en casa de otro escritor, Gudillo Kiesser, y creo que ella estaba intrigada por mí porque era la época en la que salían las notas de Gente con mi foto. Creo que tenía curiosidad y de esa curiosidad por conocerme surgió una larga amistad. Nos veíamos prácticamente todos los domingos cuando íbamos a comer a casa de ellos en Vicente López. Ella organizaba unas reuniones muy interesantes a las que invitaba a gente de todo tipo, escritores, pintores, músicos, políticos, científicos. Marta era una mujer con muchas conexiones y mucha vida social. Yo conocí a mucha gente en su casa y con algunas personas he hecho amistad. A Alberto Girri lo conocí allí y terminó siendo la única persona a la que le leía mis escritos y le pedía opinión. Girri siempre me valoraba lo que le daba, le gustara o no. Eso es difícil de encontrar.

El suicidio de Marta se produjo cuando yo estaba en Estados Unidos y fue terrible. Mi novela Los ojos azules está dedicada e ella. Yo veía que Marta estaba mal —como muy ansiosa, a veces muy desesperada - pero tenía también un lado muy escondido donde yo no podía penetrar. Una vez, poco tiempo antes de que me fuera a Estados Unidos, yo estaba trabajando y me dijo que necesitaba hablar conmigo. Yo me di cuenta de qué tenía que ser ya. Dejé todo y nos fuimos a un bar. Me senté, la miré y no me dijo nada. No pudo decirme nada. Después hablamos de pavadas, de cualquier cosa, y entonces me di cuenta de que no me quería para eso. ¿Quéme quería decir?... Antes de irme a Estados Unidos, ella, el marido y Alberto Girri me hicieron una despedida. Cuando terminamos de comer, salimos a la calle, era verano, y yo vi que Marta empezó a caminar así, como ida. Le pregunté que qué le pasaba y me dijo: "No, que yo a ustedes no los voy a ver más". Entonces le dije que volvíamos en tres o cuatro meses y ella insistía en que no nos iba a ver más: "Porque ustedes no van a volver", me decía.

M.L.: Una palabra: "viaje".

A.D.: El viaje, no sé, es como la predestinación. El viaje no se elige sino, desde un principio, te es asignado. Yo no creo mucho en los propósitos, aunque soy una persona que me me estoy poniendo objetivos y metas constantemente. Ahora tengo menos porque, finalmente, creo que vos vas por caminos que nunca te podés imaginar. Hay gente que nunca es llevada a ninguna parte y que nunca ha salido de su lugar y tampoco lo desea. Hay destinos 
itinerantes y en éstos no se puede planear nada. Todo lo que te pasa en la vida son viajes constantes que se te dan.

M.L.: ¿A dónde llegan?

A.D.: En mis libros no llegan a ninguna parte. Son viajes locos alrededor de cosas imposibles y tienen que ver con la desorientación personal. Viajamos y hay como una ola que nos lleva y nos trae. Flotamos, vamos y venimos, pero no sabemos para qué, ni hacia dónde. ¡Mirá qué iba a saber yo, nacida en Rumania, que iba a terminar en Argentina, casada con un argentino y escribiendo en castellano! Tampoco sé si Buenos Aires es mi punto final. Sé que aquí me he sentido especialmente bien por la calidez de las relaciones personales, por la confianza que te brinda le gente, por esa cosa latina. Los rumanos son divertidos, generosos y son también como los argentinos que te cuentan la vida en cinco minutos, son gente confianzuda. En Francia, sin embargo, para llegar a contarte una historia personal ... ¡Bueno! Hay bastantes parecidos entre Rumania y la Argentina. Ambos son países marginales, pero a la vez muy cultos, países de los que han surgido muchas personalidades que luego se han ido dispersando y marchando. Pero eso no lo explica todo. ¿Por qué estoy acá y si mi vida va a seguir acá? Eso no lo sé. Lo que sí creo es que un solo país es poco. Yo considero que tengo dos patrias, tres, en realidad, porque Francia también ha sido muy importante en mi educación. Se tiene esta obsesión, que es muy humana, de atarse a los símbolos pero, por las circunstancias que me tocaron vivir, yo estoy muy abierta y eso me alegra, porque mi vida me dio la posibilidad de estar en otros lugares y de ver que hay gente querible en todas partes.

M.L.: ¿Algo que unifique toda tu obra?

A.D.: Eso lo tienen que decir los analistas. En mi obra siempre hay una preocupación por la desgracia de la condición humana, por esa insatisfacción permanente y por la falta de paz que causa el deseo. También intento indagar en la tragedia humana irresoluble de que nacemos para morir. Finalmente, la vida es trágica en la medida en que no se encuentra la paz interior para realizar este viaje hasta la muerte. Creo que eso es lo fundamental en mis libros. ¿Cómo llegar a una paz interior que realmente haga que este viaje no sea tan terrible? En este viaje se nos va la vida y por eso es una responsabilidad personal y colectiva ¿qué hacés con eso que te han dado? Es demasiado complejo. En mis libros también hay un planteo ético entre el bien y el mal.

M.L.: Pero no se toma partido, ni se dan respuestas ...

A.D.: No, como yo no tengo respuesta no puedo dar ninguna. Creo que el único libro que tuvo un final más claro fue el primero, La Señora, porque la personaje de la señora termina loca e ingresa en un manicomio. Después entré en una línea de más ambigüedad. Me pareció que yo no tenía respuestas para nada y que hacer un final cerrado era como dar una versión de la realidad. En mis textos hay una preocupación ética para discernir entre el bien y el mal, pero no hay propuesta de solución. 
